\title{
Practice and Barriers of Breast Self-Examination Among Women in a Rural Community in South Western, Nigeria
}

\author{
Victoria Funmilayo Hanson ${ }^{1}$, Rabab Gad Abd El-Kader ${ }^{1} \&$ Rose Ekama Ilesanmi $^{1}$ \\ ${ }^{1}$ RAK College of Nursing, RAK Medical and Health Sciences University, United Arab Emirates \\ Correspondence: Victoria Funmilayo Hanson, Assistant Prof. of Maternal and Child Health Nursing, RAK \\ College of Nursing, RAK Medical and Health Sciences University, United Arab Emirates.
}

Received: June 3, 2019

Accepted: June 24, 2019

Online Published: July 15, 2019

doi:10.20849/ijsn.v4i3.588

URL: https://doi.org/10.20849/ijsn.v4i3.588

\begin{abstract}
Background: Breast cancer (BC) is the most common cancer and the second cause of cancer deaths in women worldwide as well as in Nigeria .The incidence of the disease appears to be rising faster in a population groups which had hitherto enjoyed low incidence, with the peak age of breast cancer in Nigerian women being about ten years earlier than Caucasians

Aim: This study investigated the practice of BSE and its possible barriers among women in a rural community in South Western area of Oyo State; Nigeria.

Study design: The study utilized Participatory Action Research (PAR) design using purposive and cross sectional sampling technique for survey and 95 women for the focus group discussion. The PAR framework involves four phases: Observe, Reflect, Plan and Act. Structured questionnaire was used for phase one, and A - 3 session FGD was used for phases on Reflect and Plan. Data was analyzed using the SPSS version 21, while content analysis for FGD to identify common themes.

Results: The study reveals that $75.1 \%$ had no knowledge of breast self-examination at all while only $24.9 \%$ had knowledge of what BSE, their sources of information was majorly health Professionals (47.5\%), electronic media (21.4\%), 76.5\% did not practice BSE. Also, about 77\% of the respondents expressed one form of barrier or another to BSE practice. Major barriers to the practice of BSE identified are revealed based on these themes: 'knowledge/awareness of BSE', 'practice and appeal for intervention', and 'misconceptions and fear of being diagnosed'.

Conclusion: More than half of the participants do not practiced BSE. Some socio demographic significantly influenced the practice of the BSE. Lack of knowledge, not having any symptoms, myths and being afraid of being diagnosed with breast cancer were the main barriers to practicing BSE. There is need to develop a continuous awareness campaign among rural women on the importance of performing BSE.
\end{abstract}

Keywords: Breast Self-Examination (BSE), knowledge, practice, women empowerment, rural women, wards/villages

\section{Introduction}

Breast cancer is a kind of cancer that grows from breast cells and the development starts from the inner lining of milk ducts (ductal carcinoma) or the lobules that supply milk (lobular carcinoma). The first noticeable symptom of breast cancer is a lump in the breast which is usually a thickened tissue in the breast. Most people take lumps in the breast to be the breast cancer itself, yet, it is not all lumps that are cancerous but could be an indication so immediately there is a lump in the breast it should be checked by a health professional. The peak age group is 40-49, accounting for nearly 40 percent of all cases Jedy-Agba (2017)). The good news is that there is evidence-based research which showed that one-third of all cancers are preventable and a further one-third, if diagnosed early, is potentially curable. This observation demands that cancer control should be of increasing priority in health care programs of developing countries (Olowokere A., Adenike Onibokun, A, and Irinoye, O. 2012) ). The identification of the challenges and barriers to the practice of BSE through this study is also expected to reduce the rate of breast cancer especially those discovered at the latter stage when little or nothing can be done about it. The outrage triggered by so many needless deaths, however, can be alleviated by hope as demands for better health care and improved quality of life for all females are being voiced out by communities, 
health personnel, researchers and policy makers. The objective of this study was to determine the practice and barriers of BSE Breast Self-Examination among the rural women.

\subsection{Aims / Objectives}

The major objectives of this study are the following:

- $\quad$ To examine practice of BSE among women in a rural community.

- To identify the barriers to the practice of BSE among the study population.

\subsection{Research Questions}

1. What is the level of practice of Breast Self-Examination, if any, among the women in rural women in a local community

2. What are the challenges and barriers to the practice of Breast Self-Examination among the rural women in a local community?

\section{Literature Review}

In Nigeria, some 100000 new cases of cancer occur every year, with high case fatality ratio With approximately $20 \%$ of the population of Africa and slightly more than half the population of West Africa, Nigeria contributed $15 \%$ to the estimated 681,000 new cases of cancer that occurred in Africa which is similar to the situation other developing countries of the world, a significant proportion of the increase in incidence of cancer in Nigeria is due death from infectious diseases ,poverty, increasing prevalence of smoking, physical inactivity, obesity as well as dietary and lifestyle patterns Adelekan, A. (2012).

In all the centers in Nigeria, except Calabar and Eruwa, breast cancer was rated first among other cancers. Further reports showed that majority of cases occurred in pre-menopausal women, and the mean age of occurrence ranged between $43-50$ years across the regions, the youngest age recorded was 16 years Adelekan, A. (2012). Other authors also reported that peak age of incidence in Nigeria is 42.6 years, of which $12 \%$ of cases occurred before 30 years. Furthermore postmenopausal women accounted for $20 \%$ of cases. Elima Jedy, Agba et al (2012) were of the opinion however that the "parameters may be more reflective of the demographic profile of Nigeria than an inherent difference in epidemiological characteristics of breast cancer in Nigeria.

$\mathrm{BSE}$ is one of the preventive interventions to date, unlike the other intervention; like Clinical Breast Examination and mammography, BSE is performed by the woman and does not need any equipment. To the best of the researcher's knowledge, studies on BSE among women in this community is currently lacking, even though some studies in Nigeria have been conducted in some urban communities

Yaro and Yakse (2013) stated that BSE is a useful and essential screening strategy, especially when used in combination with regular physical examinations by a doctor and mammography. About $20 \%$ of the time, breast cancer is found by physical examination rather than by mammography; hence, the recommendations that all women routinely perform BSE as part of their overall breast cancer screening strategy.

Mazinga, C. Nyamakura R, Ndaimani. A, Mhlanga, M. (2016) and Pilevarzadeh M. (2016) reported that BSE enables women to be take responsibility for their breast health. Thus, the lack of knowledge of the signs and symptoms of breast cancer and of BSE itself invariably leads to presenting with advanced disease.

Studies with similar outcomes are Mazinga et al (2016), who studied women in Zimbabwe in which result showed low knowledge of breast cancer examination and thus recommended increased breast cancer education and screening intervention programmes. In 2016, Agbonifoh reported a high level of practice of BSE among undergraduate students which was not consistent with findings from previous studies. All these studies reported low practice of BSE among their respondents who were from similar university settings. This suggests that women in most rural communities lack the required knowledge and therefore do not practice BSE. This was also buttressed by Amoran \&Toyobo (2015) in study among women in rural community in Nigeria. Findings indicated that even though $58.2 \%(\mathrm{n}=495)$ had heard about BSE, only $24.4 \%$ practice BSE.

\subsection{Barriers and Challenges of Women to Practicing Breast Self-Examinations}

In Amoran \& Toyobo (2015) the women in a rural community reported barriers to BSE to include perception of not being at risk (47.6\%) and lack of knowledge of how to perform BSE (47.6\%)

For women the breasts are a symbol of womanhood, they provide a social definition of being a woman and so practicing Breast Self-Examination to them connotes having breast cancer already or detection of it. Therefore, losing a breast would signify to society that these women are somehow less than a woman and that their femininity is diminished. They would prefer not to even practice it talk less of detecting the cancer. The current 
literatures from Taleghani, Kianpour, and Tabatabaiyan, (2019); Mamdouh et al. (2014), have all reported many barriers to the practice of BSE to include socio-demographic variables, attitude, awareness and knowledge of BSE itself.

A focus group discussion in Iran showed that religious boundaries, fatalism, and modesty inversely affect the performance of breast cancer screening among Muslim women (Ahmadian, 2011). In addition, destiny is a strong motive for diseases such as breast cancer. Death is assumed as God's will by most Iranian women, especially among the traditional ones and this negatively affects their attitude towards health seeking behaviors.

\section{Methodology}

\subsection{Study Setting and Population}

The study was conducted in a Nigeria rural community where women population are about one quarter including children. The participants of this study were three hundred and forty five (345) women distributed through the five selected villages, aged between 20- 60 years selected by Cross-sectional and purposive sampling. Approval was obtained after due information was provided to the women and research assistant.

\subsection{Design}

This study was conducted in four phases using the PAR framework. The first phase, "Observe", describes the knowledge, practice and barriers of BSE, was collected for this phase; the second phase, "Reflect", is a reflection on the results of the data gathered in observation and the conclusions reached. The third phase, "Plan", deals the planning suggestions from phase two and making recommendations for use in the next phase. The fourth phase, "Act", is on implementation of the recommendations. The last two phases will be discussed in a further article.

\subsection{Data Collection}

Two data collection tools were used questionnaires and interview guide were used to collect relevant information from the respondents. The questionnaire was divided into three distinct sections: A, B, C and D... Questionnaires were used to collect relevant information from the respondents, at the Observe stage of the study to elicit information on the practice and barriers of BSE among the women who can read and write. The $1^{\text {st }}$ section obtained information about socio-demographic variables on participants, (which are age, marital status, and educational qualification, characteristics of woman's occupation, religion and income status), information about the practice of early detection measures of breast cancer and reinforcement factors and the last section measures the indices of Champion Revised Health Belief Model Scale (CHBMS)

Interviews were conducted for women who cannot read nor write. The questionnaire was translated to the local language and used as interview guide to elicit the same information above on their knowledge of BSE. A question guide was used for the Focus Group Discussion (FGD) session with leading questions related to BSE and breast cancer. The aim of Focus Group Discussion, was to meet Participatory Action Research sub-stage, REFLECT and "Draw Conclusions" with participants on data collected from surveys. The question guide stated are 1.what do you know about breast cancer? 2. Do you know the various ways by which breast cancer can be prevented? 3. Have you heard about breast self-examination? If yes where? 4. Do you practice it? If yes how? 5. Are there any barriers/challenges that would prevent you from undertaking breast self-examination? 6 . What are the ways forward to encourage BSE among women? These questions are to ensure that the same questions were asked in all the focal group session. Three Focus Group Discussion sessions each were conducted with 10 participants at the health center main hall to ensure privacy and confidentiality (Ibid) in three villages

\subsection{Pilot Testing}

Before putting the questionnaire in practice a pilot study on 50 women were conducted to test the validity and reliability of the questionnaire. All comments of the participants were incorporated in the final draft of the questionnaire.

\subsection{Validity and Reliability}

The Cronbach's, alpha test of internal consistency was 0.867 , while content validity was assessed by supervisors. Member checking was used in qualitative research methodology as a mechanism for quality control, with the aim of improving the accuracy and credibility of the study.

\subsection{Procedure}

The survey was conducted in 2015 among the rural women using both English and translated questionnaire version based on the education of the women, the women took 7-10 minutes to complete the questionnaire while the Focus group had three sessions each lasting between 50 and 90 minutes. 


\subsection{Ethical Considerations}

Approval from the Community and Health Sciences Higher Degrees Committee, and ethical clearance was also granted by the Senate Research Committee of the University of Western Cape, as well as by the Ethical Review Committee of the $\mathrm{MOH}$ of the State. Written consent was obtained from the study participants . They were informed of confidentiality and their right to reject participation.

\subsection{Data Analysis}

Statistical Package for social Science (SPSS) version 21 was utilized. Data was presented by descriptive statistics in the form of frequencies, percentages, Focus Group Discussions sessions were analyzed qualitatively, discussion were transcribed, the transcription was coded and categorized to themes Thematic analysis and NVivo9 was used to manage the data.( Polit,1999).

\section{Results}

This section presents the findings of this study based on the data generated and analyzed.

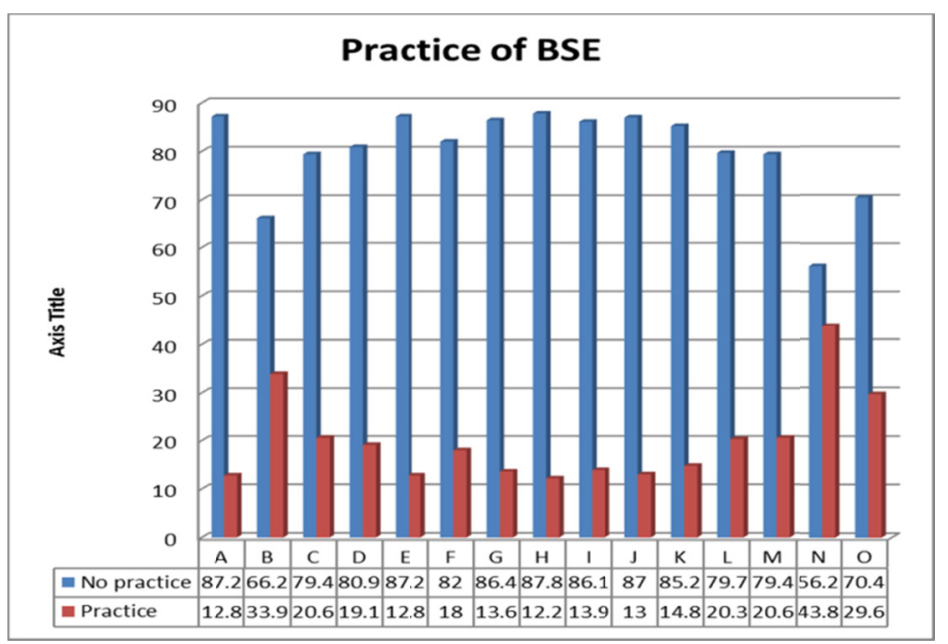

\begin{tabular}{ll}
\hline KEY & Items on practice of Breast Self-Examination \\
\hline A & Stand in front of a mirror \\
\hline B & Look at the breast and note any difference in shape, size nipple \\
\hline C & Check for swelling, increased warmth or tenderness in either breast \\
\hline D & Look at the nipples for size, shape and direction in which they point \\
\hline E & Check for rashes or sores and nipple discharge \\
\hline F & Look at breast while by putting hands over her head and presses her hands on her side \\
\hline G & Check breasts are equal in front of a mirror \\
\hline H & Lies down on bed to check the breast \\
\hline I & Look at left breast note any difference from the right breast \\
\hline J & Place pillow under left shoulder and place her arm over her head \\
\hline K & Palpate the entire breast round and note any swelling or tenderness \\
\hline L & Squeeze the nipple gently and note any discharge \\
\hline M & Do the same for the right breast sitting up and with her arms at sides \\
\hline N & Do you sit up and raise arm to palpate the tail of the breast and check for swelling or tenderness \\
\hline O & Do the same for the right side \\
\hline
\end{tabular}


Table 1. Practice of BSE

\begin{tabular}{lll}
\hline Practice of Breast self-examination & Frequency & Percent \\
\hline No practice & 264 & 76.5 \\
\hline Practice & 81 & 23.5 \\
\hline Total & 345 & 100.0
\end{tabular}

The results also showed that 264 (76.5\%) respondents did not practice BSE, while 81 (23.5\%) practised it (Table 1). This was the summarized result of the question, consisting of 14 items, on step by step process of BSE practice.

Data from the FGDs further shows the following:

Most respondents had not been practicing BSE due to lack of technical know-how. Moreover, it was equally detected that most respondents did not examine their breast for early detection in line with practice and did not even check or practice in a month. Whenever we listened to this kind of a talk, we usually inform our family who then serve as a reminder of such to us in-case of forgetfulness. "(FGD GROUP 1)

However, most women were eager to learn about the practice of examination breast SE. In this view, most respondents responded as follows:

"No, please teach us; we want to know." (FGD Group 2)

"No, we do not know how to do it, teach us" (FGD group 3)

Table 2. Barriers to BSE practice

\begin{tabular}{lll}
\hline Barriers to BSE practice & Frequency & Percent \\
\hline Perceived barrier to BSE & 265 & 76.8 \\
\hline Perceived no barrier & 80 & 23.2 \\
\hline Total & 345 & 100.0 \\
\hline
\end{tabular}

The data analysis revealed that 265 (76.8\%) of the respondents had no perception of barriers to BSE, while 80 (23.2\%) of them had knowledge of barriers to BSE.

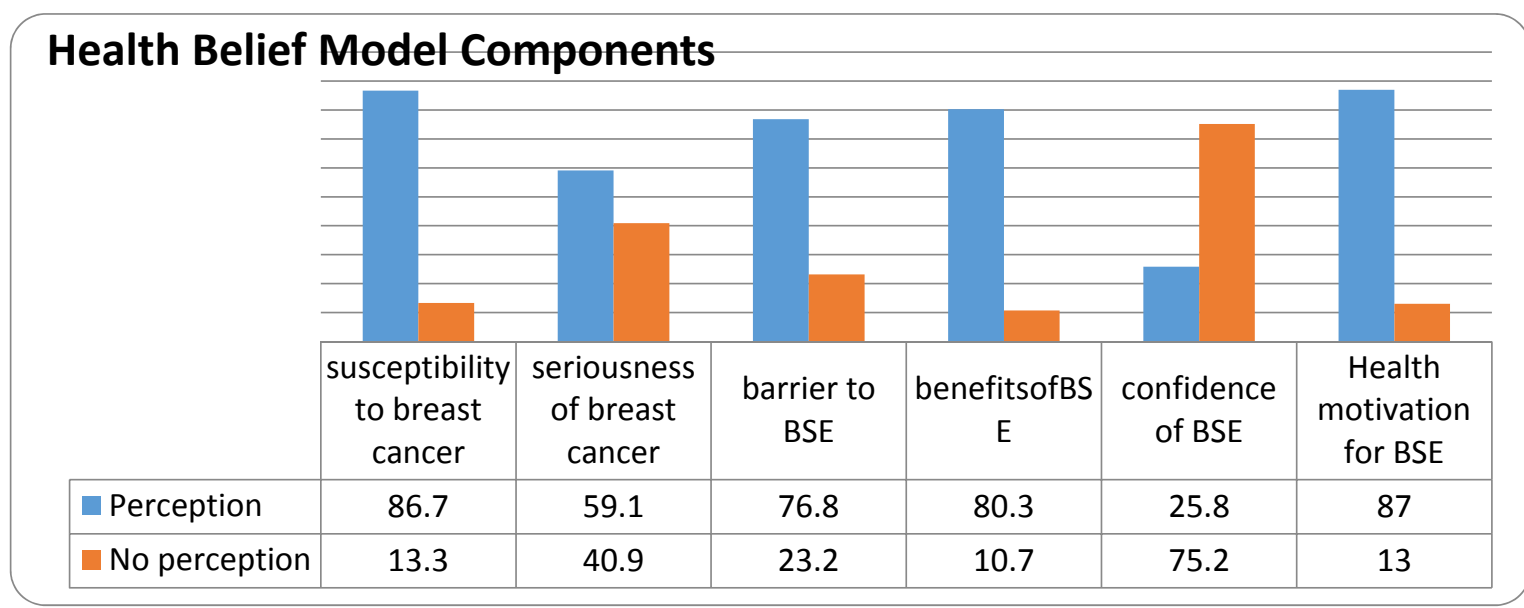

Figure 1. Respondents' perception of susceptibility, seriousness to cancer of breast, benefits, confidence and health motivation to BSE practice

The respondents' perception of susceptibility to breast cancer showed that $204(59.1 \%)$ and $299(86.7 \%)$ of them had high perception and good perception (respectively) of being susceptible to breast cancer, while 141 (40.9\%) and $46(13.3 \%)$ of them had no perception (respectively) of their susceptibility to the disease (Figure 4.3$)$. The 
result also revealed that while $68(19.7 \%)$ of the respondents had low perception on the benefits of BSE, 277 $(80.3 \%)$ had good perception of the benefits of BSE in preventing breast cancer. Moreover, $89(25.8 \%)$ of respondents were confident in performing BSE to prevent breast cancer, while $256(74.2 \%)$ of them were not confident (Figure 4.3).

Furthermore, the results showed that $45(13.0 \%)$ of the respondents were not positive that belief in health motivation can improve BSE practice; but $300(87.0 \%)$ were positive that health motivation improves the practice. This supports the necessity of an empowerment programme in the study area.

The implication of the findings in the first phase is such that $75.1 \%$ of the participants had no knowledge of BSE; $76.5 \%$ of them did not practise BSE; and $76.8 \%$ of them indicated the presence of barriers /challenges to the practice of BSE.

\section{Discussion}

Regarding the practice of breast self-examination, the American Cancer Society and other leading cancer agencies recommended monthly BSE to women (American Cancer Society .2011). The result of the study shows that more than $53.9 \%$ were categorized as poor in practicing of BSE according to Elima Jedy-Agba. et al( 2012) they noted that forty- one percent of the respondents in their study had heard or read about breast cancer, with only a few of them being aware of the signs of its early stages. Knowledge about risk factors and perception of risk was lacking. The media is one of the main sources of the respondents' information about the disease.

Finocchario-Kessler. S, Wexler. C, Maloba. M, Mabachi. N, Ndikum-Moffor. F, and Bukusi. E. (2016) in a research carried out in a local scene in Nigeria, stated that there is bridge to gap between the knowledge and the practice of breast and cervical cancer screening activities and that the association for family physicians and other regulating bodies should facilitate access to screening services. It was also discovered that lack of knowledge about Breast Self-Examination was responsible for lack of practice and also female education and free mass screening are necessary for any successful cancer screening program in Nigeria. Moreover, the result indicated, as did Finocchario-Kessler et al. (2016). Almost all the studies on knowledge, attitude and practice used survey method of data collection, with a few using quasi-experiment with results showing that risk perception and educational status increased CBE and mammography rates, as well as BSE practice; but because of insufficient BSE knowledge, the increased rate of BSE practice is often below expectation. It was recommended that nurses put forward initiatives in training programmes to increase women's BSE abilities (Olowokere et al, 2012). Perceived self-efficacy and perceived benefits are significantly related to BSE, and that Health Behavioural Model is a useful framework for identifying factors influencing the use of BSE among Iranian women (Noroozi, Jomand, and Tahmasebi 2011).

The participants' misconception that breast cancer could be attributed to breastfeeding was allayed by giving health education that breastfeeding is a normal physiological process that has nothing to do with taking care of their breasts, and that it is not a risk factor for breast disease on the contrary it prevents breast cancer. The women were also informed that taking care of their breasts is not waywardness or a sexual issue, as mentioned by some participants, but a way of ensuring that their breasts are checked for normalcy.

Some participants reported that there had been incidences of breast disease in the community. This was further corroborated by records from the health center, where cases of breast lumps had been reported in the last few years. Breast lumps (about ten cases) were removed surgically free. Findings of the current study highlight that it would be pertinent for an educational program to be developed for the women in the rural population, as a platform for teaching and learning about breast cancer matters, as well as related health issues (Yaro \& Yakse 2013). Moreover, Hurdle (2007) indicated support for the use of gender-focused educational methods with emphasis on empowerment to increase the cancer screening practices of older women

Olubodun. T, Odukoya. O and Balogun. M (2019) and Pilevarzadeh M. (2016) have reported several barriers to the practice of BSE, including socio-demographic variables, attitude, awareness and knowledge of step-by-step BSE process. Also, Tabari, et al (2017), have reported that fear of actually suffering from breast cancer often make women unwilling to practise BSE. Findings of these studies affirm that of the current study those women are fearful of having breast cancer as a consequence of self-examining their breasts. Some women feel embarrassed to examine their breasts, while others express worry about the outcome of such examination. Forgetfulness is another important factor that affected the practice of BSE. It was equally detected from the FGD that most respondents did not examine their breast for early detection in line with practice and did not even check or practice in a month due to forgetfulness. 


\section{Conclusion}

It was observed in phase one of the Participatory Action Research process that the participants' level of knowledge and practice of BSE were low. This was attributed to the lack of appropriate health information on the practice, lack of skills, fear of talking about breast cancer, embarrassment, and lack of privacy, among other factors. The study findings indicated the need for an empowerment programme that would ensure dissemination of the appropriate information and support for BSE practice to promote breast cancer prevention. The second phase of the Participatory Action Research process was used to further strengthen the result of the survey findings. This information was used in phase two for reflections during FGD sessions on the findings of phase one. Data from the FGD reflection sessions also affirmed the findings of phase one - that there was a lack of knowledge and practice of BSE, as well as the presence of barriers to the practice that had a negative impact on the participants' practise of BSE. The FGD reflective sessions also resulted in the emergence of three themes: awareness /knowledge of BSE, practice and appeal for intervention (empowerment) and facts about their misconceptions and fear.

Majority of the women believed that health motivation can improve the knowledge and practice of BSE. .Fear of breast cancer, forgetfulness to practice BSE and myths are major barriers to BSE. BSE proficiency, as an easy and cost effective secondary screening method, is still the best line of defense for women in developing countries where mammography costs are prohibitive or the procedure is not universally available.

Educational program will go a long way towards reminding women when and how to carry out BSE. Nurses and midwives should help sensitize society so that there is an awareness of women's reproductive health practices and women are better able to deal with health issues such as breast cancer. It is important that further studies are conducted in other settings in order to arrive at best practice with regard to reducing the spread of breast cancer in developing countries through BSE.

\section{Recommendations}

Based on the results of this study, the following recommendations have been made to serve as key guidelines for the early detection of breast cancer in Oyo state, Nigeria: for further study:

- It is pertinent that an educational program need to be established for the women, which will be an opportunity for those who have not heard about it to be taught and those who have heard a long time ago to be reminded in a form that will be universally accepted by all the women like a health talk in their local language, in all areas on what BSE is all about, its advantages to the promotion of long life in women leading to reduction in breast cancer which can cut off the life of the woman in the house and further that training a woman in any issue amounts to training a community and society.

- Dissemination of health information on BSE should be made available on disabusing their mind and enlightenment of women on identified barriers of BSE practice to women of reproductive age. The information should contain instructions showing step by step of BSE procedure.

- More participatory approach research design involving the beneficiary would enlighten women on how communities and households interact and share idea allowing them to have a voice in their health, and allow the beneficiaries to develop the skills and practices necessary to forge their own path and sustain the projects or programs

\section{Limitations}

Study was limited to selected community in the country hence it cannot be generalized...Never the less this study was conducted vigorously and will contribute immeasurably to the health of women in underserved community like the one studied.

\section{Acknowledgement}

Authors would like to acknowledge students who participated in the study. Conflicts of Interest Disclosure.

Authors declare that there is no conflict of interest statement.

\section{References}

Adelekan, A. (2012). Awareness, Knowledge and Practices of Breast Cancer Prevention among Women with Family History of Breast Cancer in Ede, Osun State, Nigeria. IOSR Journal of Dental and Medical Sciences, 2, 42-47. https://doi.org/10.9790/0853-0224247

Agbonifoh, J. A. (2016). Breast Self-examination practice among female students in a tertiary institution. Journal of Education \& Practice, 7(120).

Ahmadian, M. (2011). Factors Influencing Women's Participation in Breast Cancer Prevention Program in 
Tehran, Iran. Doctoral Research, Universiti Putra Malaysia.

American Cancer Society. (2011). Cancer Facts and Figures 2010. Retrieved February 23, 2011, from www.cancer.org/acs/groups

Amoran, O. E., \& Toyobo, O. O. (2015). Predictors of breast self-examination as cancer prevention practice among women of reproductive age-group in a rural town in Nigeria. Nigerian Medical Journal, 56(3), 185-189. https://doi.org/10.4103/0300-1652.160362

Champion, V. L., \& Scott, C. R. (1997). Reliability and validity of breast cancer screening belief scales in African American women. Nursing Research, 46(6), 331-337.

Costain, M., Rudo, N., Augustine, N., \& Maxwell, M. (2016). Self-care practices and stage at diagnosis of breast cancer among breast cancer patients at a Central Hospital in Zimbabwe. Journal of Dental and Medical Sciences, 15(2), 71-80.

Finocchario-Kessler, S., Wexler, C., Maloba, M., Mabachi, N., Ndikum-Moffor, F., \& Bukusi, E. (2016). Cervical cancer prevention and treatment research in Africa: a systematic review from a public health perspective. BMC Womens Health, 16, 29. https://doi.org/10.1186/s12905-016-0306-6

Jedy-Agba, E. (2017). Breast Cancer in sub-Saharan Africa: Determinants of Stage at Diagnosis and Diagnostic Delays in Women with Symptomatic Breast Cancer. School of Hygiene \& Tropical Medicine.

Jedy-Agba, E., et.al. (2002). Cancer Incidence in Nigeria: A Report from Population-based Cancer Registries. Cancer Epidemiology, 36(5), e271-e278. https://doi.org/10.1016/j.canep.2012.04.007

Mamdouh, H. M., El-Mansy, H., Kharboush, I. F., Ismail, H. M., Tawfik, M. M., El-Baky, M. A., \& Sharkawy, O. G. (2014). Barriers to breast cancer screening among a sample of Egyptian females. Journal of Family \& Community Medicine, 21(2), 119-24. https://doi.org/10.4103/2230-8229.134771

Noroozi, A., Jomand T., \& Tahmasebi, R. (2011). Determinants of breast self-examination performance among Iranian women: an application of the health belief model. Journal of Cancer Education, 26(2), 365-74.

Olowokere, A., Adenike Onibokun, A., \& Omolola Irinoye, O. (2012). Women's health beliefs and breast cancer screening practices in Nigeria. African Journal of Midwifery and Women's Health, 6(2), 91-97.

Olubodun, T., Odukoya, O., \& Balogun, M. (2019). Knowledge, attitude and practice of cervical cancer prevention, among women residing in an urban slum in Lagos, South West, Nigeria. The Pan African Medical Journal, 32, 130. https://doi.org/10.11604/pamj.2019.32.130.14432

Pilevarzadeh, M. (2016). Women's Perspective of Breast Self-examination. International Journal of Biomedical Science, 12(3), 115-119.

Polit, D., \& Hungler, B. (1999). Nursing Research: Principle and Method (6th ed.), pp. 416-417. Philadelphia: Lippincott Company.

Tabari, F., Abbaszadeh, R., Torabi, S., \& Amini, F. (2017). Barriers of breast self-examination: A review study from Iranian researchers. Bali Medical Journal, 6, 562. https://doi.org/10.15562/bmj.v6i3.639

Taleghani, F., Kianpour, M., \& Tabatabaiyan, M. (2019). Barriers to Breast Self-examination among Iranian Women. Iranian Journal of Nursing and Midwifery Research, 24(2), 108-112. https://doi.org/10.4103/ijnmr.IJNMR_94_18

Yaro, K. L., \& Yakse, N. (2013). Challenges and prospects of empowering rural women in Nigeria. African Review of Arts, Social Sciences and Education, 2(1).

\section{Copyrights}

Copyright for this article is retained by the author(s), with first publication rights granted to the journal.

This is an open-access article distributed under the terms and conditions of the Creative Commons Attribution license (http://creativecommons.org/licenses/by/4.0/). 